\title{
An Assessment of Attitudes, Behaviors, and Outcomes of Patients with Type 2 Diabetes
}

Jeanette M. Daly, RN, PhD, Arthur J. Hartz, MD, PhD, Yinghui Xu, MS, Barcey T. Levy, PhD, MD, Paul A. James, MD, Mary L. Merchant, RN, PhD, and Robert E. Garrett, MD

Objectives: Patient self-care behaviors, including taking medication, following a meal plan, exercising regularly, and testing blood glucose, influence diabetes control. The purpose of this research was to identify (1) which barriers to diabetes management are associated with problem behaviors and (2) which patient behaviors and barriers are associated with diabetes control.

Methods: This was a cross-sectional study of linked medical record and self-reported information from patients with type 2 diabetes. A randomly selected sample of 800 clinic patients was mailed an investigator-developed survey. The study sample consisted of 253 (55\%) individuals who had measured glycosylated hemoglobin (HbA1c) within 3 months of the survey date.

Results: The barriers to each diabetes self-care behavior differed. Cost was the most common barrier to the 4 self-care behaviors. In a multivariable regression model, the belief that type 2 diabetes is a serious problem and depression were strongly associated with higher HbA1c levels. Lower HbA1c levels were significantly associated with being married and greater self-reported adherence-satisfaction with taking medication and testing blood glucose.

Conclusion: This study expanded earlier research by focusing on 4 specific self-care behaviors, their barriers, and their association with HbA1c. Barriers that were significantly associated with HbA1c were specific to the behavior and varied across behaviors. (J Am Board Fam Med 2009;22:280-90.)

Although the importance of glycemic control is well established, ${ }^{1}$ it is often not achieved. ${ }^{2}$ Factors contributing to poor control include inadequacies in patient self-care behaviors, medical management, or both. ${ }^{3-7}$ Physicians know that patient self-care behaviors influence diabetes control but may lack training for and interest in motivating their patients to improve these behaviors. ${ }^{8}$ Contributing to poor control is a paucity of information available about the frequency of problem behaviors, barriers to appropriate care behaviors, or the relationship of specific patient self-care behaviors to glycemic control. ${ }^{9,10}$

Our conceptual model for this study is shown in Figure 1, adapted from the works of Glasgow. ${ }^{11}$

This article was externally peer reviewed.

Submitted 28 May 2008; revised 2 October 2008; accepted 9 October 2008.

From the Department of Family Medicine, University of Iowa (JMD, YX, BTL, PAJ, MM, REG) and the Department of Medicine, University of Utah (AJH).

Funding: This product was supported by grant no. 5 RO3 HS014410 from the US Department of Health and Human Services, Agency for Health Care Research and Quality.

Conflict of interest: none declared.

Corresponding author: Jeanette Daly, 01290-F PFP, 200 Hawkins Drive, Iowa City, IA 52242 (E-mail: jeanettedaly@uiowa.edu).
Factors that influence diabetes adherence in our model include personal factors, such as type and duration of diabetes, illness, and other health conditions and psychosocial factors. Glasgow's model places primary emphasis on the variables of the patient-health care provider interactions, compliance, and outcomes. The patient-provider interactions are composed of the patient's perspective and participation, appropriateness of prescriptions, and clarity and specificity of recommendations. The social/environmental influences included barriers to adherence, community resources, social support, and economic factors. The primary emphases of this study were the performance of 4 primary self-care behaviors and specific barriers to these behaviors: (1) medication use, (2) meal plans, (3) exercise, and (4) home glucose testing. In addition, our model attempts to include many important concepts related to management of diabetes, including family support, physician-patient communication, motivation and confidence to manage diabetes, mental/physical health, and diabetes knowledge (see Figure 1). The purpose of this research was to determine (1) which barriers to diabetes management were associated with the 


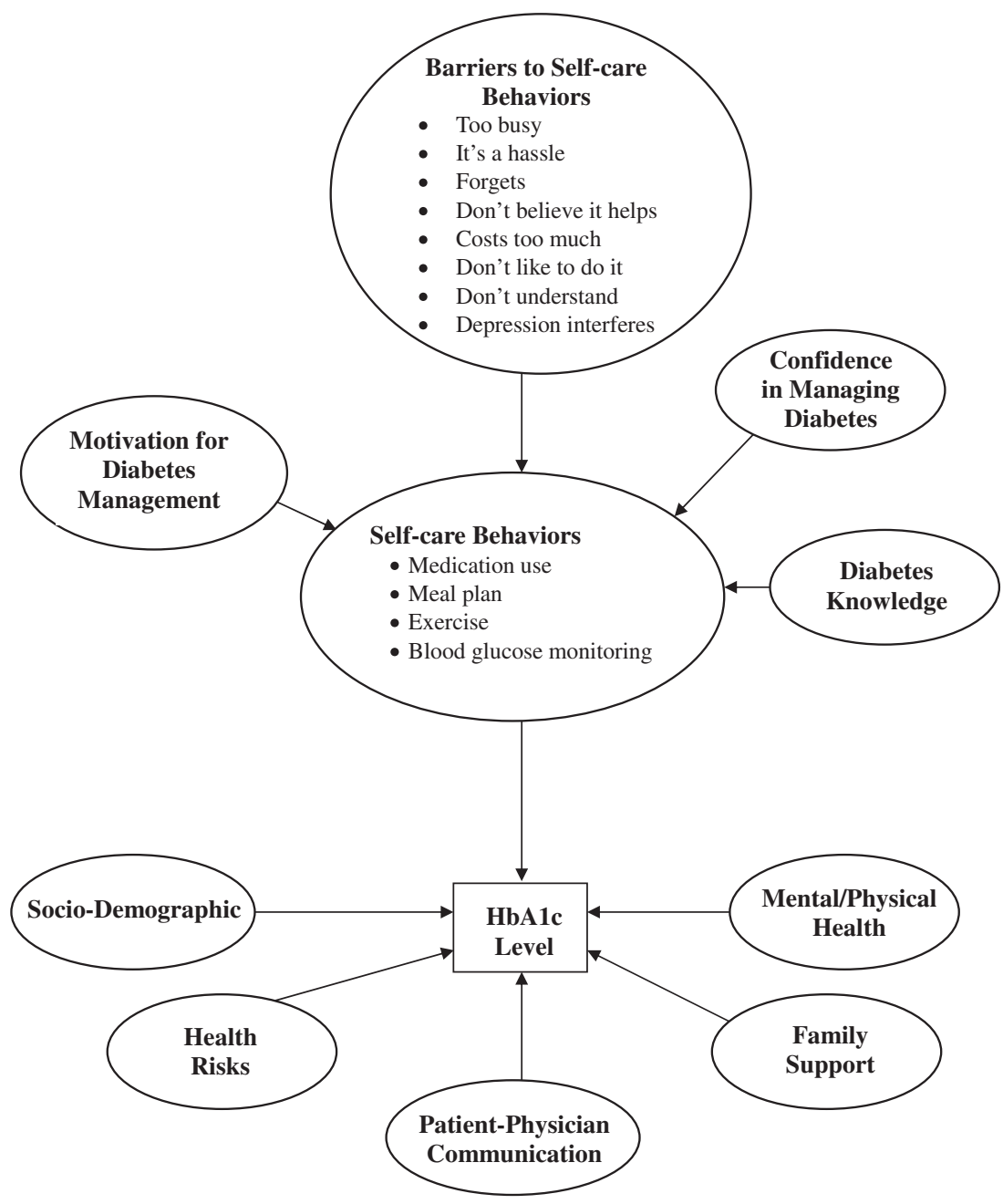

Figure 1. Conceptual model for factors influencing HbA1c.

problem behaviors and (2) which patient behaviors and barriers are associated with diabetes control as measured by glycosylated hemoglobin (HbA1c).

\section{Methods \\ Patients}

All patients with the diagnosis of type 2 diabetes being followed in primary care outpatient clinics at a midwestern medical center were identified as potential participants. Inclusion criteria for participation were a diagnosis of type 2 diabetes and at least 2 outpatient visits to the clinic within the previous 12 months to establish that the patient was a regular clinic patient. Of the 2889 identified patients, in 2003 a random sample of 800 patients who met inclusion criteria were mailed a 12-page investigator-developed questionnaire, 2 informed consent documents (one to keep), and a stamped return envelope. Study questionnaires and consents were returned by 458 patients ( $57 \%$ response rate). To be able to relate self-care behaviors with HbA1c, the final sample consisted of 253 individuals who had an HbA1c measured in the 3-month interval before or after the questionnaire mailing $(55 \%$ of those who returned surveys). The other $205 \mathrm{pa}-$ tients who returned a questionnaire had $\mathrm{HbAlc}$ outside of the 3 -month time window and were a priori selected for correlation of questionnaire responses with HbA1c. The study and methods were approved by the University of Iowa Institutional Review Board. 


\section{Diabetes Self-Care Bebaviors and Barriers Instrument Development}

An interdisciplinary team of faculty and staff from the Carver College of Medicine Departments of Family Medicine and Division of Endocrinology within the Department of Internal Medicine, the College of Pharmacy, and the College of Public Health at the University of Iowa collaborated to develop a comprehensive instrument to assess selfcare behaviors and related barriers.

We developed the patient questionnaire entitled "Self-Care Behaviors Survey for Patients with Diabetes" composed of 141 questions in 7 domains (see Table 1). This instrument was created using selected questions from 20 existing diabetes questionnaires identified using a MEDLINE search and by investigator-developed questions. ${ }^{11-30}$ Components of the following instruments were included: (1) Summary of Diabetes Self-Care Activities ${ }^{16}$; (2) the Diabetes Care Profile ${ }^{22}$; (3) the Diabetes Empowerment $\mathrm{Scale}^{23}$; (4) the Diabetes Attitude $\mathrm{Scale}^{24}$; (5) Diabetes Family Behavior Checklist ${ }^{25}$; (6) Environmental Barriers to Adherence Scale ${ }^{26}$; (7) Self-Efficacy to Perform Self-Management Behaviors $^{27}$; (8) Provider Participatory DecisionMaking Style ${ }^{31}$; (9) Patient Perception of PatientCenteredness $^{29}$; and (10) The Diabetes Educational Profile. ${ }^{30,32}$ The final questionnaire also contained the 9-item Patient Health Questionnaire (PHQ-9), a self-administered version of the Primary Care Evaluation of Mental Disorders depression module, ${ }^{33}$ and the 12 -item Short-Form Health Survey, ${ }^{34}$ measuring physical and mental component summary scales. ${ }^{35}$

Using the Flesch-Kincaid readability scale, the readability of the developed questionnaire was at grade level $6.1 .^{36,37}$ The average time for individuals to complete the questionnaire was 19 minutes (SD \pm 8.9 minutes). Cronbach's $\alpha$ for the 34 questions addressing barriers to diabetes management (listed in Figure 1) was 0.95.

\section{Outcomes}

Study outcomes were patient self-reported self-care behaviors and HbA1c measurements. The main outcome, $\mathrm{HbA1c}$, has a controlled range of $4.8 \%$ to $6.0 \%$, and all measurements were done by the same Clinical Laboratory Improvement Amendmentscertified pathology laboratory.

Self-care behaviors were classified in 2 ways: (1) percentage of time the patients adhered to medica- tion, meal plan, exercise, and glucose testing plans during the past month and (2) the level of satisfaction with each of the preceding domains. From these 2 measures a combined adherence satisfaction score for each domain was created, as detailed below.

A combined dichotomous adherence satisfaction score was created for each specific self-care behavior (medication, meal plan, exercise, and glucose testing) by combining 2 question responses: the patient's reported adherence (percentage of time did activity in past month) and their satisfaction with each behavior (rating scale, $0=$ not satisfied to $5=$ very satisfied). A patient had to have both high adherence and high satisfaction with a given behavior to receive a high adherence-satisfaction score. Because of the distribution of adherence ratings, high adherence (percentage of time patient performed activity during the past month) with taking medication was defined as $99 \%$ to $100 \%$, following a meal plan was $90 \%$ to $100 \%$, glucose testing was $95 \%$ to $100 \%$, and exercise was $\geq 3$ days per week for at least 30 minutes per session. High satisfaction with the performance of each behavior was defined as satisfied (rating of 4) or very satisfied (rating of 5). If a patient had missing data for either the adherence or satisfaction score, their response was not included in the created adherence-satisfaction scores. If a participant reported high performance in one category and not the other, the response was categorized as a low adherence-satisfaction score. If a participant reported high satisfaction in one category and a low performance, the response was categorized as a low adherence-satisfaction score.

Barriers to each self-care behavior were measured using a scale of 1 (no extent) to 5 (a very great extent). Dichotomous variables were created for each barrier such that the barrier was considered a significant problem if the patient rated it a 4 or a 5 .

\section{Chart Review}

Chart reviews were conducted electronically for patients who returned a completed questionnaire and who also returned a signed informed consent. Variables included sex, age, height, weight, medications, and most recent HbA1c level.

\section{Data Analysis}

The main outcome variables, HbA1c and combined adherence-satisfaction with each self-care behavior, were tested for an association with each potential 


\begin{tabular}{|c|c|}
\hline Variable & Description \\
\hline \multicolumn{2}{|l|}{ Sociodemographic } \\
\hline Age & Years old \\
\hline Race & White versus all other races \\
\hline Sex & Male versus female \\
\hline Marital status & Married versus unmarried \\
\hline Living arrangement & Lives alone versus does not live alone \\
\hline Education & $\begin{array}{l}\text { High school diploma or less; some college/college graduate/some masters/ } \\
\text { masters graduate or terminal degree }\end{array}$ \\
\hline Income & $\$ 0-\$ 19,999 ; \$ 20,000-\$ 69,999 ;$ or $\geq \$ 70,000$ \\
\hline Insurance & Has insurance versus has no insurance \\
\hline \multicolumn{2}{|l|}{ Family support } \\
\hline Family knowledge and support & $\begin{array}{l}8 \text { questions about family helping patient cope with diabetes (family provides } \\
\text { helps and support with diabetes, knows about diabetes, helps you follow a } \\
\text { meal plan, take medication, care about your feet, get enough exercise, } \\
\text { test blood glucose, and handle your feelings about diabetes) Rated using } \\
\text { scale of } 1 \text { (none) to } 5 \text { (a lot) }\end{array}$ \\
\hline \multicolumn{2}{|l|}{ Health risks } \\
\hline Tobacco use & Smokes cigarettes versus does not smoke cigarettes \\
\hline Duration of diabetes & $\begin{array}{l}\text { Patient reports number of years since they have been diagnosed with } \\
\text { diabetes }\end{array}$ \\
\hline Body mass index & Weight $(\mathrm{kg})$ divided by the height $\left(\mathrm{m}^{2}\right)$ \\
\hline \multicolumn{2}{|l|}{ Mental/physical health } \\
\hline SF-12 Health Survey & Summary scores for mental and physical health ${ }^{35}$ \\
\hline Depressive symptoms & $\begin{array}{l}\text { PHQ-9, sum of score on } 9 \text {-question scale }(0=\text { not at all to } 3=\text { nearly } \\
\text { every day; scale range } 0-27)^{33} \text {; higher score indicates more depressive } \\
\text { symptoms }\end{array}$ \\
\hline \multicolumn{2}{|l|}{ Physician-patient communication } \\
\hline Physician-patient relationship & $\begin{array}{l}12 \text { questions: sees the same physician; physician explains diabetes to patient; } \\
\text { patient agrees with physician's opinion; patient is given opportunities to } \\
\text { answer questions; patient feels comfortable asking questions; patient } \\
\text { issatisfied with physician discussions; physician asks about goals for } \\
\text { treatment; patient is offered a choice for treatment; physician explains } \\
\text { treatment to patient; physician explores how manageable this treatment } \\
\text { would be for the patient; physician discusses patient's and physician's } \\
\text { respective roles; and physician encourages the role the patient wants in } \\
\text { their care. } \\
\text { Rated using scale: } 1 \text { (no extent) to } 5 \text { (very great extent) }\end{array}$ \\
\hline \multicolumn{2}{|l|}{ Self-care behaviors } \\
\hline Adherence-satisfaction to medications & $\begin{array}{l}\text { Combination percent adherence with medications and satisfaction with } \\
\text { adherence }\end{array}$ \\
\hline Adherence-satisfaction to meal plans & $\begin{array}{l}\text { Combination percent adherence with meal plan and satisfaction with } \\
\text { adherence }\end{array}$ \\
\hline Adherence-satisfaction to blood glucose testing & $\begin{array}{l}\text { Combination percent adherence with testing blood glucose and satisfaction } \\
\text { with adherence. Patient reports yes/no to testing blood glucose at home }\end{array}$ \\
\hline Adherence-satisfaction with regular exercise & $\begin{array}{l}\text { Combination days/week exercised, minutes exercised/day and satisfaction } \\
\text { with adherence }\end{array}$ \\
\hline \multicolumn{2}{|l|}{ Potential barriers to diabetes management } \\
\hline $\begin{array}{l}\text { Barriers to taking medications, following meal } \\
\text { plan, testing, blood glucose, and } \\
\text { exercising, regularly (total of } 34 \text { questions) }\end{array}$ & $\begin{array}{l}8 \text { questions about medications, meal plans, testing blood glucose, and } \\
\text { exercise (too busy; hassle; don't believe; don't like to do; don't } \\
\text { understand; forgets; costs too much; depression interferes) } \\
\text { Rated using scale: } 1 \text { (no extent) to } 5 \text { (very great extent) } \\
2 \text { questions (hurts; don't understand how to use results) about testing } \\
\text { blood glucose } \\
\text { Rated using scale: } 1 \text { (no extent) to } 5 \text { (very great extent) }\end{array}$ \\
\hline Diabetes knowledge & $\begin{array}{l}5 \text { questions about the importance of testing blood glucose (to what extent } \\
\text { type } 2 \text { diabetes is a serious disease; importance of keeping blood glucose } \\
\text { close to normal; keeping blood glucose close to normal is too much } \\
\text { work; and need to know about diabetes to make good decisions) } \\
\text { Rated using scale: } 1 \text { (no extent) to } 5 \text { (very great extent) }\end{array}$ \\
\hline
\end{tabular}




\begin{tabular}{ll}
\hline Variable & Description \\
\hline $\begin{array}{l}\text { Confidence in ability to manage self-care } \\
\text { behaviors }\end{array}$ & $\begin{array}{l}4 \text { questions related to medication, meal plan, blood glucose, and exercise } \\
\text { Rated using scale: } 1 \text { (not very confident) to } 5 \text { (very confident) } \\
\begin{array}{l}\text { Motivation to do a better job in self-care } \\
\text { behaviors }\end{array}\end{array}$ \\
$\begin{array}{l}4 \text { questions related to medication, meal plan, blood glucose, and exercise } \\
\text { Rated using scale: } 1 \text { (not very motivated) to } 5 \text { (very motivated) }\end{array}$ \\
\hline
\end{tabular}

${ }^{*} \mathrm{R}^{2}=0.24$.

SF-12, 12 -item Short-Form Health Survey; PHQ-9, 9-item Patient Health Questionnaire.

predictor variable (see Table 1). Spearman correlation coefficients were used to assess the relationship between outcome and predictor variables. Univariate analyses using $t$ tests or a one-way analysis of variance were used to assess significant differences in mean $\mathrm{HbA1c}$ by different categories.

Multivariable linear regression was used to identify predictors of HbA1c. Variables whose univariate correlation with HbA1c was significant at $P<$ .10 were considered for inclusion in the multivariable regression model. The PROC REG procedure with a forward stepwise selection method was used to identify significant and independent predictors of HbA1c. Predictor variables that remained significant at the $P<.05$ were entered to determine the coefficients in the final model.

\section{Results}

The overall response rate to the mailed questionnaire was 458 (57\%) of 800 mailed questionnaires. The 253 patients (32\%) who had a HbA1c result documented during the 3 -month interval before or after the mailing comprised the final study group (55\% of those who returned surveys). Mean HbA1c for the study group was $7.1 \%$, with a range of $4.9 \%$ to $15.4 \%$. There were no differences in age and sex between patients who gave informed consent and those who did not. There was no difference in age, sex, or educational level between patients who had a HbA1c within 3 months of the survey initiation or completion and those who did not. Those married had a lower HbA1c in the study group and for patients who returned the survey but who did not have a HbAlc within 3 months of the survey initiation or completion. HbA1c was significantly lower for the study group (mean, 7.08) than for the 143 remaining patients who completed the questionnaire and did not have a HbAlc within 3 months of the questionnaire (mean, 7.54; $P=.013$ ).

The study group population was $85 \%$ white and $57 \%$ female; $53 \%$ were married; $53 \%$ had an an- nual income $<\$ 20,000 ; 52 \%$ had some college education; $28 \%$ lived alone; and $20 \%$ had no health insurance. The mean age was 60.2 years. Higher HbA1c levels were significantly associated with lower age and not being married (see Table 2). HbA1c was not associated with living arrangements, insurance coverage, or income.

The mean duration of time since the diagnosis of diabetes was 10.1 years. Body mass index (BMI) values for participants ranged from 20 to $82 \mathrm{~kg} / \mathrm{m}^{2}$ (mean, $36 \mathrm{~kg} / \mathrm{m}^{2}$ ). Higher HbA1c levels were significantly correlated with a longer duration of having diabetes $\left(\mathrm{r}_{\mathrm{s}}=0.25 ; P<.001\right)$ and a higher BMI $\left(\mathrm{r}_{\mathrm{s}}=0.16, P<.01\right)$. No association was found between HbA1c levels and smoking status.

Table 2 shows other variables significantly associated with $\mathrm{HbA1c}$ at the univariate level. Two of 8 family support items were significantly associated with lower HbA1c. One of the 12 physician-patient communication items was significantly associated with lower HbA1c.

The mean value for the PHQ-9 score was 7.9 (SD, 7.03) for the study group. Higher PHQ-9 scores were significantly correlated with higher HbA1c $\left(\mathrm{r}_{\mathrm{s}}=0.22 ; P=.001\right)$. A higher HbA1c was significantly associated with poorer general mental health perceptions on the 12-item Short-Form Health Survey (see Table 2).

Participants were taking an average of 9 (SD \pm 5.02 ) prescribed medications other than oral hypoglycemics or insulin. The mean and modal number of oral hypoglycemic agents taken was 1 . Thirty-three percent of the patients were on some insulin: $17 \%$ used a single type of insulin, $16 \%$ took 2 types of insulin, and one participant used 3 types.

\section{Self-Care Bebaviors and HbA1c}

Participant adherence and the relationship between the 4 self-care behaviors and HbAlc are depicted in Table 3. Participants reported the highest performance adherence with taking their medications as 


\begin{tabular}{|c|c|c|c|}
\hline Domains & Categories (n) & Mean HbA1c (\%) & $P$ \\
\hline \multicolumn{4}{|l|}{ Socio-Demographics } \\
\hline \multirow[t]{3}{*}{ Age (years) } & $29-49(\mathrm{n}=34)$ & 7.74 & .004 \\
\hline & $50-64(\mathrm{n}=137)$ & 7.10 & \\
\hline & $65-89(\mathrm{n}=82)$ & 6.79 & \\
\hline \multirow[t]{2}{*}{ Marital status } & Married (n = 129) & 6.90 & .026 \\
\hline & Not married $(\mathrm{n}=112)$ & 7.33 & \\
\hline \multirow[t]{2}{*}{ Years since diagnosis of diabetes } & $\leq 6(\mathrm{n}=110)$ & 6.77 & .002 \\
\hline & $>6(\mathrm{n}=115)$ & 7.28 & \\
\hline \multicolumn{4}{|l|}{ Family support } \\
\hline \multirow[t]{2}{*}{ Family provides help and support } & Lesser extent $(\mathrm{n}=111)$ & 7.39 & .003 \\
\hline & Greater extent $(n=126)$ & 6.82 & \\
\hline \multirow[t]{2}{*}{ Family knows about diabetes } & Lesser extent $(\mathrm{n}=96)$ & 7.37 & .014 \\
\hline & Greater extent $(n=141)$ & 6.87 & \\
\hline \multicolumn{4}{|l|}{ Mental/physical health } \\
\hline \multirow[t]{3}{*}{ Depression* } & No depression $(\mathrm{n}=145)$ & 6.86 & .007 \\
\hline & Atypical depression $(\mathrm{n}=45)$ & 7.19 & \\
\hline & Major depression $(\mathrm{n}=63)$ & 7.53 & \\
\hline \multirow[t]{3}{*}{$\mathrm{SF}-12 \mathrm{MCS}^{\dagger}$} & $<40(\mathrm{n}=58)$ & 7.37 & .078 \\
\hline & $40-50(\mathrm{n}=53)$ & 7.25 & \\
\hline & $>50(\mathrm{n}=102)$ & 6.86 & \\
\hline \multicolumn{4}{|l|}{ Physician-patient communication } \\
\hline \multirow{2}{*}{$\begin{array}{l}\text { Patient feels comfortable asking physician questions } \\
\text { about diabetes }\end{array}$} & Lesser extent $(\mathrm{n}=35)$ & 7.71 & .039 \\
\hline & Greater extent $(n=207)$ & 7.01 & \\
\hline \multicolumn{4}{|l|}{ Barriers to diabetes management } \\
\hline \multirow[t]{2}{*}{ Cost of taking medication } & Lesser extent $(n=169)$ & 6.99 & .005 \\
\hline & Greater extent $(\mathrm{n}=39)$ & 7.98 & \\
\hline \multirow[t]{2}{*}{ Depression interferes with taking medication } & Lesser extent $(n=185)$ & 7.02 & .012 \\
\hline & Greater extent $(\mathrm{n}=20)$ & 8.62 & \\
\hline \multirow[t]{2}{*}{ Cost of following meal plan } & Lesser extent $(\mathrm{n}=172)$ & 6.97 & .038 \\
\hline & Greater extent $(n=42)$ & 7.66 & \\
\hline \multirow[t]{2}{*}{ Depression interferes with following meal plan } & Lesser extent $(\mathrm{n}=193)$ & 7.01 & .045 \\
\hline & Greater extent $(\mathrm{n}=21)$ & 8.20 & \\
\hline \multirow[t]{2}{*}{ Cost of testing blood glucose } & Lesser extent $(n=185)$ & 7.04 & .006 \\
\hline & Greater extent $(\mathrm{n}=25)$ & 7.90 & \\
\hline \multirow[t]{2}{*}{ Depression interferes with testing blood glucose } & Lesser extent $(\mathrm{n}=192)$ & 7.01 & .021 \\
\hline & Greater extent $(n=14)$ & 9.16 & \\
\hline \multirow{2}{*}{$\begin{array}{l}\text { Extent to which diabetes is considered a serious } \\
\text { disease }\end{array}$} & Lesser extent $(n=30)$ & 6.62 & .006 \\
\hline & Greater extent $(\mathrm{n}=213)$ & 7.18 & \\
\hline \multirow{2}{*}{$\begin{array}{l}\text { Confident with following meal plan as } \\
\text { recommended }\end{array}$} & Lesser extent $(n=95)$ & 7.41 & .002 \\
\hline & Greater extent $(n=124)$ & 6.81 & \\
\hline
\end{tabular}

\footnotetext{
*Depression as measured by the 9-item Patient Health Questionnaire. Major depression was either the first or second question with a rating of $\geq 2$ and a totalscore $>10$. Atypical depression was both the first 2 questions with a rating of $<2$ and a total score of $\geq 10$; either the first or second question with a rating of $>2$ and $\leq 5$ and a total score $<10$; or the last question with a rating of $\geq 1$ and a total score of $<9$.

${ }^{\dagger}$ Substantially below average health $=$ physical component summary-12 score $<40$; somewhat below average health $=$ physical component summary-12 score of 40 to $<50$; and above average health = physical component summary-12 score of $\geq 50$.

SF-12, 12-item Short-Form Health Survey; MCS, mental component summary.
} 
Table 3. Self-care Behavior's Performance and Association of Glycosylated Hemoglobin (HbA1c) with Mean Adherence, Satisfaction, and Adherence-Satisfaction to Specific Self-Care Behaviors

\begin{tabular}{|c|c|c|c|c|c|}
\hline & $\begin{array}{c}\text { Self-Care Behavior } \\
\text { Adherence }\end{array}$ & $\begin{array}{c}\text { Spearman Correlation } \\
\text { of HbA1c with } \\
\text { Adherence }\end{array}$ & $\begin{array}{c}\text { Spearman Correlation } \\
\text { of HbAlc with } \\
\text { Satisfaction }\end{array}$ & $\begin{array}{c}\text { Spearman Correlation } \\
\text { of Combined } \\
\text { Adherence- } \\
\text { Satisfaction }\end{array}$ & $\begin{array}{c}\text { HbAlc with } \\
\text { Adherence-Satisfaction } \\
\text { Mean HbAlc (n) }\end{array}$ \\
\hline $\begin{array}{l}\text { Taking } \\
\text { medication }\end{array}$ & $96 \%$ & $-0.25^{\ddagger}$ & -0.12 & $-0.45^{\ddagger}$ & $\begin{array}{l}\text { High: } 6.87(168)^{\dagger} \\
\text { Low: } 7.91(46)\end{array}$ \\
\hline $\begin{array}{l}\text { Following a meal } \\
\text { plan }\end{array}$ & $66 \%$ & $-0.21^{\dagger}$ & $-0.29^{\ddagger}$ & $-0.68^{\ddagger}$ & $\begin{array}{l}\text { High: } 6.5952)^{\ddagger} \\
\text { Low: } 7.26(154)\end{array}$ \\
\hline $\begin{array}{l}\text { Testing blood } \\
\text { glucose }\end{array}$ & $81 \%$ & -0.12 & -0.12 & $-0.75^{\ddagger}$ & $\begin{array}{l}\text { High: } 6.93(123)^{\dagger} \\
\text { Low: } 7.40(90)\end{array}$ \\
\hline Exercising & 52 minutes per week & -0.03 & $-0.16^{*}$ & $-0.71^{\ddagger}$ & $\begin{array}{l}\text { High: } 6.99(66) \\
\text { Low: } 7.05(122)\end{array}$ \\
\hline
\end{tabular}

${ }^{*} P \leq .05,{ }^{\dagger} P \leq .01,{ }^{\ddagger} P \leq .001$ for higher adherence, satisfaction, adherence-satisfaction being associated with lower HbA1c.

The reported adherence was a percentage of time completed activity in past month, with the exception of exercise, which was mean minutes per week. The reported satisfaction was measured on a rating scale of $0=$ no satisfaction to $5=$ very satisfied.

directed $96 \%$ of the time, on average (see Table 3, column 2). Those participants who reported higher adherence with taking medications and following meal plans had lower HbA1c (see Table 3, column 3). Following a meal plan had the highest correlation with $\mathrm{HbA1c}$ as compared with the other selfcare behaviors (see Table 3, column 4).

Mean satisfaction scores were highest for taking medications (4.58); scores were 4.02 for testing blood glucose, 3.29 for following a meal plan, and were lowest for exercising regularly (2.91). Greater satisfaction scores with following a meal plan and exercising regularly were significantly associated with lower HbA1c levels (see Table 3, column 5). Combined adherence-satisfaction scores were associated with lower HbA1c for all 4 self-care behaviors (see Table 3, column 6).

\section{Barriers to Diabetes Management}

Eight barriers to diabetes management were assessed for the self-care behaviors of taking medication, following a meal plan, and exercising regularly (see Table 4). Two additional barriers were listed for monitoring blood glucose. For all 4 self-care behaviors, one barrier- "it costs too much"-was significantly associated with higher HbA1c levels. "Depression interferes" was another barrier associated with higher HbA1c levels for 3 self-care behaviors.

Participants who indicated that type 2 diabetes is a very serious disease were significantly more likely to have higher HbA1c. Greater confidence in the ability to follow a meal plan was significantly correlated with a lower $\mathrm{HbA1c}$, as was greater motivation to exercise regularly (see Table 2).

Table 4. Spearman Correlations between Barriers of Each Self-Care Behavior and Glycosylated Hemoglobin (HbA1c)

\begin{tabular}{lcccc}
\hline $\begin{array}{l}\text { Barrier was a } \\
\text { Significant Problem* }\end{array}$ & $\begin{array}{c}\text { Taking Medication } \\
(r)\end{array}$ & $\begin{array}{c}\text { Following a Meal } \\
\text { Plan }(r)\end{array}$ & $\begin{array}{c}\text { Monitoring Blood } \\
\text { Glucose }(r)\end{array}$ & $\begin{array}{c}\text { Exercising Regularly } \\
(r)\end{array}$ \\
\hline Costs too much & $0.22^{\S}$ & $0.21^{\ddagger}$ & $0.23^{\S}$ & $0.17^{\dagger}$ \\
Hassle & 0.08 & $0.26^{\S}$ & $0.14^{\dagger}$ & 0.11 \\
Forgot & $0.13^{\dagger}$ & $0.17^{\ddagger}$ & 0.06 & 0.05 \\
Depression & $0.21^{\ddagger}$ & $0.18^{\ddagger}$ & $0.16^{\dagger}$ & 0.11 \\
$\quad$ interferes & & & & 0.04 \\
Too busy & 0.07 & $0.14^{\dagger}$ & $0.15^{\dagger}$ & 0.04 \\
Don't understand & 0.004 & $0.18^{\ddagger}$ & $0.15^{\dagger}$ & 0.04 \\
Don't like & 0.05 & $0.14^{\dagger}$ & $0.16^{\dagger}$ & 0.18 \\
It hurts & N/A & N/A & $0.15^{\dagger}$ & N/A \\
Don't know how to & N/A & N/A & N/A \\
$\quad$ use results & & & 0.12 & 0.06 \\
Don't believe & 0.07 & 0.13 & & \\
\hline
\end{tabular}

*Barriers were rated from 1 to 5 , with 5 indicating the item was a barrier to a greater extent.

${ }^{\dagger} P \leq .05 ;{ }^{\ddagger} P \leq .01 ;{ }^{\circledR} P \leq .001$. 
Table 5. Final Multivariate Regression Model for Factors Associated with Glycosylated Hemoglobin (HbA1c)

\begin{tabular}{lcc}
\hline Variables & Coefficient & $P$ \\
\hline Married versus not married & -0.46 & .016 \\
PHQ-9 total score (0-27) & 0.04 & .005 \\
Medication adherence-satisfaction & -0.90 & .001 \\
$\quad$ high versus low & & \\
Test blood glucose adherence- & -0.40 & .042 \\
$\quad$ satisfaction high versus low & & \\
$\begin{array}{l}\text { Belief that type 2 diabetes is } \\
\quad \text { serious disease }\end{array}$ & 0.27 & .049 \\
\hline
\end{tabular}

PHQ-9, 9-item Patient Health Questionnaire.

\section{Linear Regression Model for Predictors of HbA1c}

Variables that showed significant association with HbA1c at $P<.10$ in the univariate analysis were examined further using multivariable linear regression. Table 5 shows the final model $\left(\mathrm{R}^{2}=0.24\right)$. Variables significantly and independently associated with lower HbAlc included being married, higher adherence-satisfaction with medication, and higher adherence-satisfaction with testing blood glucose. Higher PHQ-9 scores and the belief that type 2 diabetes is a serious disease were significantly and independently associated with higher HbA1c. For example, after controlling all other variables in the model, the mean HbAlc was $0.46 \%$ lower for married patients compared with those who were not married $(P<.016)$. After controlling for all other predictors in the model, HbA1c was $0.04 \%$ higher for every 1-point increase in the PHQ-9 score in this study $(P<.005)$.

The PHQ-9 depression score was significantly correlated with financial barriers, with a coefficient of $0.45(P<.0001)$. In the $t$ test, PHQ-9 mean score was 11.51 for patients with financial barriers compared with 5.33 for those without financial barriers $(P<.0001)$.

\section{Discussion}

Previous studies have identified patient and provider barriers to glycemic control. ${ }^{5,9,10,38-41}$ This study expands earlier studies by evaluating a comprehensive group of barriers to self-care behaviors and testing their association with HbA1c levels. Barriers significantly associated with self-care behaviors were different by self-care behavior and in the expected direction. The self-care behaviors of following a meal plan and monitoring blood glu- cose had the most significant barriers. Even though distinct barriers were associated with each self-care behavior, no barriers remained in the final regression model.

Patients in this study had diabetes for an average of 10 years and more than a third had HbAlc higher than $7 \%$. Univariate analysis indicated that predictors in each domain of our conceptual model were associated with $\mathrm{HbAlc}$. Though some of the important variables in the univariate analyses (age, marital status) are not modifiable by the health care team, others (BMI, physical health, depression, family support, physician-patient communication) may be impacted by health care providers. It is possible that improving patients' overall health status, with particular attention paid to depression and weight control, could lead to improvements in their level of glycemic control. Physicians and other health care professionals who care for diabetics should make every effort to offer care plans that are acceptable and realistic for patients, as well as ensure that their patients understand what they are supposed to do.

Better physician-patient communication was found to be associated with better glycemic control. Physicians with good communication should be making an effort to provide significant positive feedback to patients who achieve good adherence to care plans. Understanding the components of specific physician-patient communication that motivate improved self-care behavior is a potential area for future study.

Sociodemographic characteristics of younger age and being single were associated with higher $\mathrm{HbA1c}$, as were lack of family support, measures of depression, poor mental health, and a poor physician-patient relationship (patients does not feel comfortable asking questions). These findings were similar to those of previous studies, ${ }^{19,39,40,42-44}$ which do not present a comprehensive model of factors associated with diabetes management. The final regression model found that being single and having higher depression scores, lower adherencesatisfaction with taking medication, lower adherence-satisfaction with testing blood glucose, and believing that type 2 diabetes is a serious disease were statistically significant and independently associated with higher HbA1c levels.

Barrier identification is critical in enhancing self-care behaviors to manage diabetes and minimize adverse effects. ${ }^{45,46}$ In this study, the main 
barriers across most self-care behaviors were cost and depression. These 2 variables were highly correlated with each other. Whether financial issues lead to depression or if depression results from diabetes needs to be evaluated. Kaholokula and colleagues $^{44}$ suggest that depression is a consequence rather than a cause of high HbA1c. Depression as measured by the PHQ-9 and as an individual barrier to 3 self-care behaviors (all but regular exercise) was significantly associated with higher HbAlc in univariate analyses, and higher scores on the PHQ-9 remained in the final model. The knowledge that depression interferes with specific self-care behaviors is important because perhaps patients' compliance could improve if the depression was treated.

Higher adherence-satisfaction with taking medication and testing blood glucose were strongly associated with lower HbA1c levels. Overcoming barriers to these self-care behaviors may lead to an improvement in HbAlc. Further studies should examine for association with $\mathrm{HbA1c}$ the patient's perception of the physician's recommendation for frequency of home glucose testing and the compliance with the physician's specific recommendations. Determining whether a person is adherent with recommended home glucose testing requires that the physician's recommendation be known, but physicians often do not explicitly document this.

Diabetes management requires knowledge and understanding of what to do and when and how to do it. Because the belief that type 2 diabetes is a very serious disease was associated with higher HbA1c, those persons with worse control may realize that they have a serious disease. As Bodenheimer and colleagues ${ }^{47}$ indicate, collaborative care and self-management education are important aspects of the physician-patient relationship and physicians working with patients to set their initial goals and action plan are important.

As a result of this work, the combined adherence-satisfaction score was created for each selfcare behavior. A stronger reflection of measure was provided for each of the 4 self-care behaviors in that a patient reports their actual performance of adherence and their satisfaction with the performance. For example, a patient reported taking medications as directed $92 \%$ of the time and rated satisfaction with taking the medication at a 4 (sat- isfied). This combination presents 2 views of the measure.

Limitations of this study include a relatively small sample of patients from a midwestern academic health center and the use of cross-sectional data that can only demonstrate an association and not causality. Future work with more diverse populations would help to determine whether the factors found here to be associated with $\mathrm{HbAlc}$ are consistent across populations. In addition, adherence was measured by self-report rather than more direct measures such as using pharmacy refill information or actual attendance at an exercise center. Self-reported medication adherence was reliable when compared with pill counts. ${ }^{47}$

\section{Conclusion}

This work demonstrates that there are significant barriers to diabetes self-care behaviors that are associated with higher HbA1c levels. Developing interventions to reduce these barriers and improve performance of self-care behaviors may be logical for diabetes trials. It is not surprising that an analysis of factors influencing successful adherence to diabetes care plans would find a wide range of factors to be important to achieving good adherence. One of the most important factors-the cost of managing a patient's diabetes-is not easily within the influence of the physician or the diabetes care team. However, health care providers can educate patients about the care plan and its rationale, or take steps to treat and alleviate depression. Either of these poses major obstacles to good glycemic control. It is reasonable to hypothesize that efficient, comprehensive intervention by the health care team in these areas will result in improvements in glycemic control. Future research on specific steps to address these treatment areas will help to clarify this question and may improve health outcomes for persons with diabetes. Clearly, as the national epidemic of diabetes continues to grow, effective tools to help patients adhere to their diabetes care regimens will be critical.

\section{References}

1. Intensive blood-glucose control with sulphonylureas or insulin compared with conventional treatment and risk of complications in patients with type 2 diabetes (UKPDS 33). UJ Prospective Diabetes Study (UKPDS) Group. Lancet 1998;352:837-54.

2. Weiner J, Parente ST, Garnick DW, Fowles J, Law- 
thers AG, Palmer RH. Variation in office-based quality: a claims-based profile of care provided to medicare patients with diabetes. JAMA 1995;273: 1503-8.

3. Rhee MK, Slocum W, Ziemer DC, et al. Patient adherence improves glycemic control. Diabetes Educ 2005;31:240-50.

4. Schwedes U, Siebolds M, Mertes G; SMBG Study Group. Meal-related structured self-monitoring of blood glucose: effect on diabetes control in noninsulin-treated type 2 diabetic patients. Diabetes Care 2002;25:1928-32.

5. Hiss RG. Barriers to care in noninsulin-dependent diabetes mellitus. The Michigan experience. Ann Intern Med 1996;124(1 Pt 2):146-8.

6. Spann SJ, Nutting PA, Galliher JM, et al. Management of type 2 diabetes in the primary care setting: a practice-based research network study. Ann Fam Med 2006;4:23-31.

7. Parchman ML, Romero RL, Pugh JA. Encounters by patients with type 2 diabetes-complex and demanding: an observational study. Ann Fam Med 2006;4:40-5.

8. Ziemer DC, Miller CD, Rhee MK, et al. Clinical inertia contributes to poor diabetes control in a primary care setting. Diabetes Educ 2005;31:564-71.

9. Dalewitz J, Khan N, Hershey CO. Barriers to control of blood glucose in diabetes mellitus. Am J Med Qual 2000;15:16-25.

10. Jerant A, von Friederichs-Fitzwater MM, Moore M. Patients' perceived barriers to active self-management of chronic conditions. Patient Educ Couns 2005;57:300-7.

11. Glasgow R. Social-environmental factors in diabetes: barriers to diabetes self-care. In: Bradley C, ed. Handbook of psychology and diabetes. Chur Switzerland: Harwood Academics Publishing;1994:33549.

12. Kristal AR, Shattuck AL, Henry HJ. Patterns of dietary behavior associated with selecting diets low in fat: reliability and validity of a behavioral approach to dietary assessment. J Am Diet Assoc 1990;90:21420.

13. Hurley AC, Shea CA. Self-efficacy: strategy for enhancing diabetes self-care. Diabetes Educ 1992;18: $146-50$.

14. Toobert DJ, Glasgow RE, Strycker LA, Barrera M Jr, Ritzwoller DP, Weidner G. Long-term effects of the Mediterranean lifestyle program: a randomized clinical trial for postmenopausal women with type 2 diabetes. Int J Behav Nutr Phys Act 2007;4:1.

15. Toobert DJ, Glasgow RE. Problem solving and diabetes self-care. J Behav Med 1991;14:71-86.

16. Toobert DJ, Hampson SE, Glasgow RE. The summary of diabetes self-care activities measure: results from 7 studies and a revised scale. Diabetes Care 2000;23:943-50.

17. Jones PM, Remley C, Engberg RA. Development and testing of the barriers to self-monitoring blood glucose scale. Diabetes Educ 1996;22:609-16.

18. Talbot F, Nouwen A, Gingras J, Gosselin M, Audet $\mathrm{J}$. The assessment of diabetes-related cognitive and social factors: the Multidimensional Diabetes Questionnaire. J Behav Med 1997;20:291-312.

19. Heisler M, Bouknight RR, Hayward RA, Smith DM, Kerr EA. The relative importance of physician communication, participatory decision making, and patient understanding in diabetes self-management. J Gen Intern Med 2008;17:243-52.

20. Reliability and validity of a diabetes quality-of-life measure for the diabetes control and complications trial (DCCT). The DCCT Research Group. Diabetes Care 1988;11:725-32.

21. Glasgow RE, Toobert DJ, Riddle M, Donnelly J, Mitchell DL, Calder D. Diabetes-specific social learning variables and self-care behaviors among persons with type II diabetes. Health Psychol 1989; 8:285-303.

22. Fitzgerald JT, Davis WK, Connell CM, Hess GE, Funnell MM, Hiss RG. Development and validation of the Diabetes Care Profile. Eval Health Prof 1996; 19:208-30.

23. Anderson RM, Funnell MM, Fitzgerald JT, Marrero DG. The Diabetes Empowerment Scale: a measure of psychosocial self-efficacy. Diabetes Care 2000;23: 739-43.

24. Anderson RM, Donnelly MB, Gressard CP, Dedrick RF. Development of diabetes attitude scale for health-care professionals. Diabetes Care 1989;12: $120-7$.

25. Glasgow RE, Toobert DJ. Social environment and regimen adherence among type II diabetic patients. Diabetes Care 1988;11:377-86.

26. Irvine AA, Saunders JT, Blank MB, Carter WR. Validation of scale measuring environmental barriers to diabetes-regimen adherence. Diabetes Care 1990; 13:705-11.

27. Lorig K, Stewart A, Ritter P, Gonzalez V, Laurent $\mathrm{D}$, Lynch J. Outcome measures for health education and other health care interventions. Thousand Oaks (CA): Sage Publications, Inc.; 1996.

28. Kaplan SH, Greenfield S, Gandek B, Rogers WH, Ware JE Jr. Characteristics of physicians with participatory decision-making styles. Ann Intern Med 1996;124:497-504.

29. Stewart M, Brown JB, Donner A, et al. The impact of patient-centered care on outcomes. J Fam Pract 2000;49:796-804.

30. Davis WK, Hess GE, Harrison RV, Hiss RG. Psychosocial adjustment to and control of diabetes mellitus: differences by disease type and treatment. Health Psychol 1987;6:1-14.

31. Kaplan SH, Gandek B, Greenfield S, Rogers W, Ware JE. Patient and visit characteristics related to physicians' participatory decision-making style. Re- 
sults from the Medical Outcomes Study. Med Care 1995;33:1176-87.

32. Hess GE, Davis WK, Harrison RV. A diabetes psychosocial profile. Diabetes Educ 1986;12:135-40.

33. Kroenke K, Spitzer RL, Williams JB. The PHQ-9: validity of a brief depression severity measure. J Gen Intern Med 2001;16:606-13.

34. Ware J Jr, Kosinski M, Keller SD. A 12-Item ShortForm Health Survey: construction of scales and preliminary tests of reliability and validity. Med Care 1996;34:220-33.

35. Ware JE, Kosinski M. Interpreting SF-36 summary health measures: a response. Qual Life Res 2001;10: 405-13; discussion 415-20.

36. Doak C, Doak LG, Root JH. Teaching patients with low literacy skills, 2nd ed. Philadelphia: J.B. Lippincott; 1996.

37. Kincaid J, Fishburne RP, Rogers RL, Chissom BS. Derivation of new readability formulas (Automated Readability Index, Fog Count, and Flesch Reading Ease Formula) for Navy enlisted personnel. Research Branch report. Memphis (TN): Naval Air Station; 1975.

38. Nagelkerk J, Reick K, Meengs L. Perceived barriers and effective strategies to diabetes self-management. J Adv Nurs 2006;54:151-8.

39. Vijan S, Stuart NS, Fitzgerald JT, et al. Barriers to following dietary recommendations in Type 2 diabetes. Diabet Med 2005;22:32-8.

40. Chlebowy DO, Garvin BJ. Social support, self-effi- cacy, and outcome expectations: impact on self-care behaviors and glycemic control in Caucasian and African American adults with type 2 diabetes. Diabetes Educ 2006;32:777-86.

41. Aikens JE, Bingham R, Piette JD. Patient-provider communication and self-care behavior among type 2 diabetes patients. Diabetes Educ 2005;31:681-90.

42. Anderson RJ, Freedland KE, Clouse RE, Lustman PJ. The prevalence of comorbid depression in adults with diabetes: a meta-analysis. Diabetes Care 2001; 24:1069-78.

43. Rubin RR, Ciechanowski P, Egede LE, Lin EH, Lustman PJ. Recognizing and treating depression in patients with diabetes. Curr Diab Rep 2004;4:119_ 25.

44. Kaholokula JK, Haynes SN, Grandinetti A, Chang HK. Biological, psychosocial, and sociodemographic variables associated with depressive symptoms in persons with type 2 diabetes. J Behav Med 2003;26: 435-58.

45. Sprague MA, Shultz JA, Branen LJ, Lambeth S, Hillers VN. Diabetes educators' perspectives on barriers for patients and educators in diabetes education. Diabetes Educ 1999;25:907-16.

46. Whittemore R, Chase SK, Mandle CL, Roy C. Lifestyle change in type 2 diabetes a process model. Nurs Res 2002;51:18-25.

47. Bodenheimer T, Lorig K, Holman H, Grumbach K. Patient self-management of chronic disease in primary care. JAMA 2002;288:2469-75. 